\title{
JOURNAL.RU
}

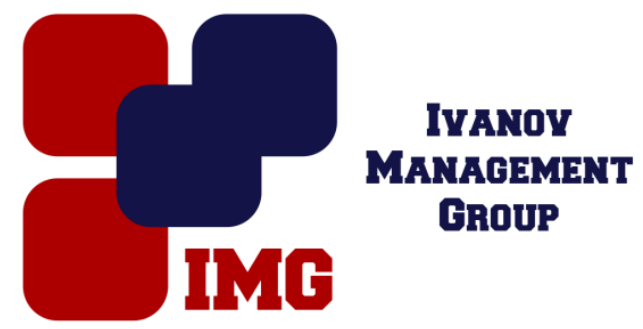

Кораблев Д.К., Кубенин Н.А., Трифонов В.А. Военно-морской политехнический институт ВУНЦ ВМФ «Военно-морская академия» Санкт-Петербург, Россия

doi: 10.18411/1j-30-06-2017-11

idsp 000001:1j-30-06-2017-11

\section{Модель обоснования состава сил поиска противника в море с привлечением беспилотных летательных аппаратов}

\section{Аннотация}

В статье предлагается способ применения беспилотных летательных аппаратов в целях поиска и обнаружения надводных морских объектов на обширных морских территориях. Выявляется зависимость необходимого состава поисковой группы из беспилотных летательных аппаратов от времени при поиске возможных надводных целей в указанных районах.

Ключевые слова: Военно-морской флот, беспилотные летательные аппараты, поиск противника в море.

Введение. Одной из задач, решаемых силами ВМФ в море, является задача обнаружения и поиска. При осуществлении поиска кораблём надводного объекта с помощью радиолокационной станции (РЛС) дальность обнаружения зависит, в том числе, и от высоты установки антенны РЛС, и не превышает нескольких десятков километров. В определённой степени этого недостатка лишены авиационные средства обнаружения, обладающие к тому же более высокой поисковой скоростью, $\mathrm{a}$, следовательно, и поисковой производительностью. Однако пилотируемая авиация не всегда может быть привлечена к решению поставленных задач. Применительно к периоду боевых действий можно сказать, что урон от потери пилотируемого аппарата не сопоставим с уроном от потери беспилотного летательного аппарата (БПЛА) в силу возможных человеческих жертв. Учитывая, что современные БПЛА могут нести РЛС, обладающие большой дальностью обнаружения, имеют высокую 
автономность и скорость полёта, представляет определённый интерес оценка эффективности использования БПЛА для поиска надводных целей.

Постановка задачи. В зоне ответственности флота ожидается появление противника в составе главной цели и сил охранения. Необходимо сформировать наряд сил из ударных кораблей и беспилотных летательных аппаратов, способный обнаружить противника, следить за ним и поразить главную цель в случае поступления приказа. При этом вероятность поражения должна быть не менее чем РЗАД, а время от принятия решения на поражение цели до залпа- не более $\Delta \mathrm{T}$. Определить состав наряда сил, который был бы способен выполнить эту задачу.

Математическая модель. Пусть скорость главной цели равна VЦ, период обследования района - ТЦ, а радиус возможного места цели на момент ее обнаружения - R0. Этот радиус расплывается в соответствии с формулой [1]

$$
R_{M Ц}(t)=R_{0}+V_{Ц} \cdot t
$$

где $\mathrm{t}$ - время с момента последнего обнаружения цели.

Обозначим радиус поражения цели - RПOP, момент передачи команды на поражение цели $-\tau$, а время на подготовку залпа - $\Delta$ ППЗ. Будем считать, что цель будет поражена с вероятностью РЗАД, если на момент залпа $\left(t=\tau+\Delta t_{\Pi 3}\right) \mathrm{RПOP}$ не меньше, чем RMЦ(t),

$$
R_{0}+V_{L} \cdot t \leq R_{\text {ПОР }}
$$

Если неравенство (2) выполняется, то залп будет произведён в момент времени t. При этом цель будет поражена с вероятностью РЗАД. Если неравенство (2) не выполняется, то необходимо ждать уточнения координат цели. Следовательно, период обследования района (время от момента потери контакта до момента окончания обследования района, в ходе которого контакт с целью будет восстановлен) должен быть таким, чтобы время от момента выдачи команды на поражение цели до момента залпа не превышало $\Delta \mathrm{T}$.

Представим задачу графически, рисунок 1 . На этом рисунке: 0, ТЦ, 2×ТЦ, $3 \times$ ТЦ - моменты окончания обследования района, временные отрезки от 0 до t1, от Тц до t2, от 2Тц до t3 и т.д. это время после потери контакта в течение которого цель (в случае поступления соответствующего приказа) будет поражена, поскольку радиус её возможного места меньше радиуса поражения, а моменты $\mathrm{t} 1, \mathrm{t} 2, \mathrm{t} 3$ соответствуют условиям

$$
R_{0}+V_{L} \cdot\left(t_{i}-(i-1) \cdot T_{L}\right)=R_{\text {ПOP }} .
$$




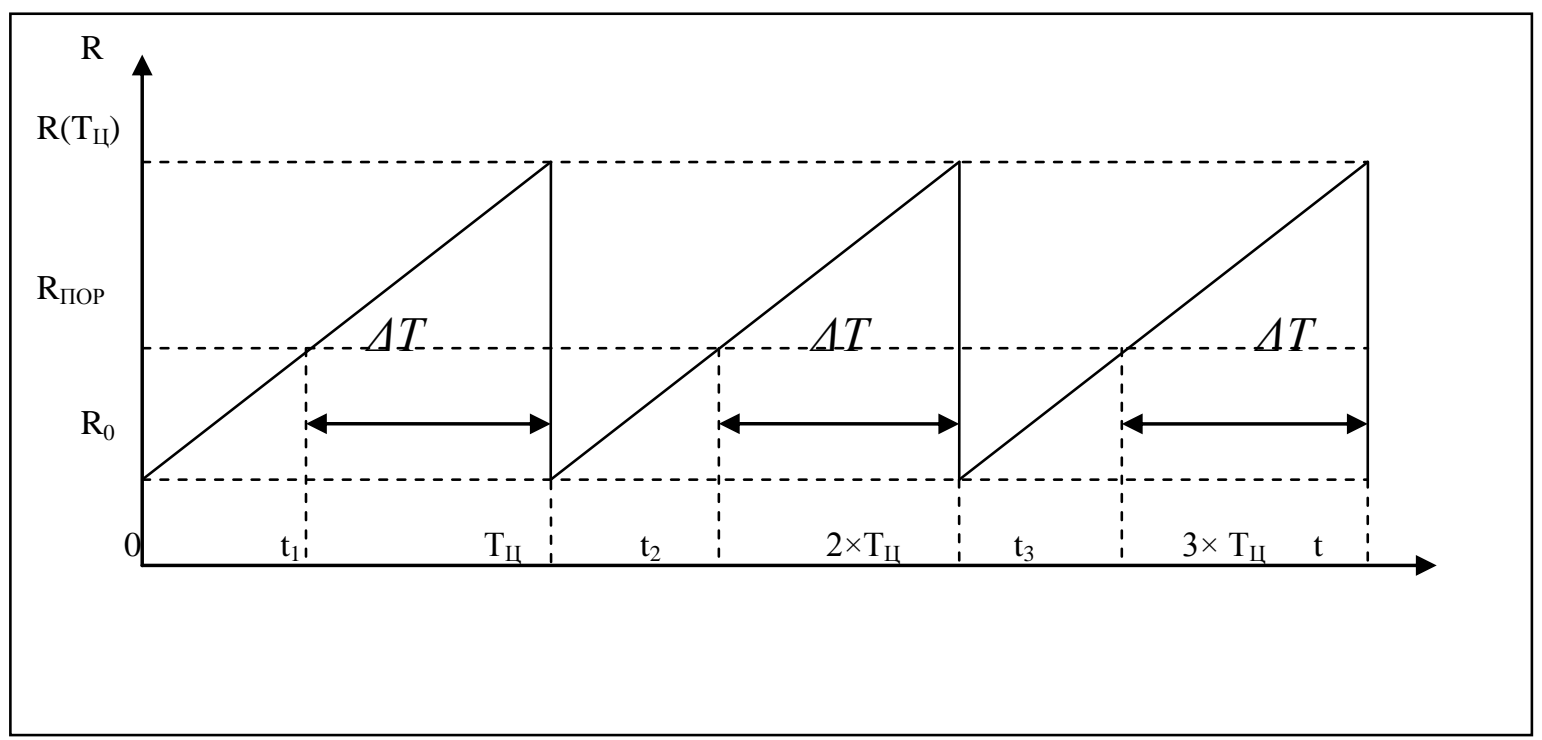

Рисунок 1 - График вариаџии радиуса возможного места ичели

В дальнейшем откажемся от индексов, и речь будем вести только о первом цикле, отображенном на рис. 1. В этом случае уравнение (3) примет вид $R_{0}+V_{L} \cdot t=R_{\text {ПоР }}$. Отсюда получим

$$
t=\left(R_{\text {ПOР }}-R_{0}\right) / V_{L} .
$$

Из рисунка 1 следует, что неравенство (2) эквивалентно неравенству $\tau+\Delta t_{\Pi 3} \leq t$. Это значит, что если момент времени $\tau$ удовлетворяет последнему неравенству, то наряд начнёт подготовку к залпу сразу же с получением команды и выполнит его через $\Delta t_{\Pi 13}$. Если же имеет место неравенство, $\tau+\Delta t_{\Pi \text { Iз }}>t$, то необходимо подождать пока не будут уточнены координаты главной цели. По условиям задачи это должно произойти не более чем через $\Delta T=T_{L}-t=T_{L}-\left(R_{\text {ПоР }}-R_{0}\right) / V_{L}$. Отсюда получим

$$
T_{L}=\Delta T+\left(R_{\text {ПOР }}-R_{0}\right) / V_{L} .
$$

Формула (5) позволяет рассчитать минимально необходимый наряд сил системы освещения обстановки, который способен решить задачу своевременного обнаружения противника. Один из вариантов такого расчета приведен ниже. Пусть для обследования района выделено $\mathrm{n}$ тактических единиц. Каждая і-я единица характеризуется поисковой скоростью vi и дальностью обнаружения цели di. Пусть площадь обследуемого района S. Тогда длительность обследования будет равна

$$
T_{L}=\left(S-\sum_{i=1}^{n} \pi \cdot d_{i}^{2}\right) \div\left(\sum_{i=1}^{n} 2 \cdot d_{i} \cdot v_{i}\right)
$$


В формуле (6) автор произвёл допущение - зоны обследования поисковых единиц не имеют пересечений.

Объединив формулы (5) и (6), получим

$$
\left(\Delta T+\left(R_{\text {ПОР }}-R_{0}\right)\right) / V_{L}=\left(S-\sum_{i=1}^{n} \pi \cdot d_{i}^{2}\right) \div\left(\sum_{i=1}^{n} 2 \cdot d_{i} \cdot v_{i}\right) .
$$

Bсе переменные в этой формуле, кроме $\mathrm{n}$ известны. Отсюда можно найти n. Очевидно, что n будет зависеть, помимо прочего, от поисковых скоростей и дальностей обнаружения тактических единиц. Поэтому здесь возможна оптимизация состава сил поиска [2]. Задача упрощается, если корабли и БПЛА, входящие в поисковый наряд сил, однотипны. В этом случае формула (7) преобразуется к виду

$$
\begin{aligned}
& \left(\Delta T+\left(R_{\text {ПОР }}-R_{0}\right)\right) / V_{\text {ЦL }}=\left(S-n_{\kappa} \cdot \pi \cdot d_{\kappa}^{2}-n_{\text {била }} \cdot \pi \cdot d_{\text {бпиа }}^{2}\right) \div \\
& \left(2 \cdot n_{\kappa} \cdot d_{\kappa} \cdot v_{\kappa}+2 \cdot n_{\text {бпиа }} \cdot d_{\text {бпа }} \cdot v_{\text {била }}\right)
\end{aligned}
$$

В случае использования одного корабля и нескольких БПЛА формула (8) преобразуется к виду

$$
\begin{aligned}
& \left(\Delta T+\left(R_{\text {ПОР }}-R_{0}\right)\right) / V_{\text {L }}=\left(S-\pi \cdot d_{\kappa}^{2}-n_{\text {била }} \cdot \pi \cdot d_{\text {бпиа }}^{2}\right) \div \\
& \left(2 \cdot d_{\kappa} \cdot v_{\kappa}+2 \cdot n_{\text {бпиа }} \cdot d_{\text {била }} \cdot v_{\text {бпиа }}\right)
\end{aligned}
$$

Откуда получим

$$
\begin{aligned}
& n_{\text {била }}=\left(S \cdot V_{u}-V_{u} \cdot \pi \cdot d_{\kappa}^{2}-2 \cdot d_{\kappa} \cdot v_{\kappa} \cdot\left(\Delta T-R_{\text {пор }}+R_{0}\right)\right) \div \\
& \left(2 \cdot d_{\text {била }} \cdot v_{\text {бпиа }} \cdot\left(\Delta T+R_{\text {пор }}-R_{0}\right)+\pi \cdot d_{\text {бпиа }}^{2} \cdot V_{u}\right)
\end{aligned} .
$$

Общее количество потребных сил

$$
\begin{aligned}
& n=1+n_{\text {бпла }}=1+\left(S \cdot V_{u}-V_{u} \cdot \pi \cdot d_{\kappa}^{2}-2 \cdot d_{\kappa} \cdot v_{k} \cdot\left(\Delta T-R_{\text {пор }}+R_{0}\right)\right) \div \\
& \left(2 \cdot d_{\text {бпиа }} \cdot v_{\text {била }} \cdot\left(\Delta T+R_{\text {пор }}-R_{0}\right)+\pi \cdot d_{\text {бпиа }}^{2} \cdot V_{u}\right)
\end{aligned}
$$

Данная формула позволяет рассчитать наряд сил, если суммарное время поиска не превышает автономность БПЛА. В противном случае, количество БПЛА необходимо будет удвоить (простейший вариант, в случае приближения суммарного времени поиска к максимальной продолжительности полёта следует заблаговременно выслать следующую группу БПЛА).

Дальность обнаружения зависит, в том числе, от дальности прямой видимости. Возможно оценить уменьшение времени обследования района и потребный наряд сил, учитывая большую поисковую скорость БПЛА, а также большую дальность прямой видимости без учёта нормальной рефракции [4], рассчитываемую по формуле (11) 


$$
D=3.57\left(\sqrt{h_{a}}+\sqrt{h_{u}}\right)
$$

где $h_{a}$ - высота антенны, м, $h_{u}$ - высота цели, м, D- дальность прямой видимости, Км.

Произведём расчёт периода обследования района площадью, равной половине площади Баренцева моря ( 712000 км2), одиночным кораблём (V-18 узлов, высота антенны 10 м) и БПЛА (V-200 км/ч, высота полёта 1000 м). Период обследования рассчитан по формуле (6), дальность обнаружения- по формуле (12). Для БПЛА время обследования составит 13 час 20 мин 15 с, а для корабля 471 час 39 мин 23 с, что чрезмерно много.

Предположим, что для обследования района выделен наряд сил, состоящий из одного ударно-поискового корабля и нескольких БПЛА.

Преобразуя формулу (6), можно оценить потребное количество БПЛА для различных назначенных периодов обследования района:

$$
n_{\text {бпла }}=\left(S-\pi \cdot d_{\kappa}^{2}-2 \cdot d_{\kappa} \cdot v_{\kappa} \cdot T_{u}\right) \div\left(2 \cdot T_{u} \cdot d_{\text {бпла }} \cdot v_{\text {бпла }}+\pi \cdot d_{\text {бпла }}^{2}\right)
$$

Результаты представлены в таблице (1):

Таблица 1.

Потребное количество БПЛА для обследования района площуадью 712000 км2 (половина площзади Баренщева моря) в назначенный период времени

\begin{tabular}{|c|c|c|c|}
\hline $\begin{array}{c}\text { Назначенный период } \\
\text { обследования, час }\end{array}$ & $\begin{array}{c}\text { Потребное } \\
\text { количество БПЛА, } \\
\text { шт. }\end{array}$ & $\begin{array}{c}\text { Назначенный период } \\
\text { обследования, час }\end{array}$ & $\begin{array}{c}\text { Потребное } \\
\text { количество БПЛА, } \\
\text { шт. }\end{array}$ \\
\hline 1 & 8 & 13 & 1 \\
\hline 2 & 5 & 14 & 1 \\
\hline 3 & 4 & 15 & 1 \\
\hline 4 & 3 & 16 & 1 \\
\hline 5 & 3 & 17 & 1 \\
\hline 6 & 3 & 18 & 1 \\
\hline 7 & 2 & 19 & 1 \\
\hline 8 & 2 & 20 & 1 \\
\hline 9 & 2 & 21 & 1 \\
\hline 10 & 2 & 22 & 1 \\
\hline 11 & 2 & 23 & 24 \\
\hline
\end{tabular}

Таким образом, включение в состав наряда сил БПЛА позволит значительно сократить время обследования района, а, следовательно, и оперативность решения задачи.

Выводы. Приведенная математическая модель является упрощенным агрегированным отображением реальных зависимостей. Однако, как отмечено в [1], во многих случаях достаточно иметь агрегированные модели, дающие 
качественную картину взаимосвязей основных свойств сложной организационно-технической системы.

$* * *$

1. Захаров И. Г. Теория принятия компромиссных решений при исследовательском проектировании судов. СПб: 1 ЦНИИ МО, 2004 - 215 с.

2. Куватов В. И., Величко Г. А. Исследование операций. СПб: ВМИРЭ, 2005- 356 с.

3. Осипов А.Н., Кириллов А.Л. Бородин И.В. Модели систем освещения обстановки на море. Петродворец: ВМИРЭ, 2001 - 156 с.

4. Буров Н.И., Маловысотная радиолокация. М, Воениздат, 1977- 128 с. 